AWEJ for Translation \& Literary Studies, Volume3, Number2.May 2019

Pp.139-151

DOI: http://dx.doi.org/10.24093/awejtls/vol3no2.12

\title{
Domestication Versus Foreignization: The case of translating Al-Sanea's Girls of Riyadh into English
}

\author{
Salwa Alwafai \\ Department of English,College of Arts \\ Imam Abdulrahman Bin Faisal University (IAU) \\ Dammam, Saudi Arabia
}

\begin{abstract}
This paper aims to shed more insights onto the relationship between ideology and literary translation through analyzing and exposing scandalous stories of girls of Riyadh in Al-Sanea's novel (2005) and its English translation (2007). It tackles how the idea of over-domestication could manipulate the source text and sometimes change its core message for commercial and ideological reasons. It addresses the following question: how (un)faithful is the published English translation of Al-Sanea's Girls of Riyadh to the original Arabic text in terms of evoking the same conceptual frames and maintaining the same lexico-grammatical relations. A frame-based cognitive analysis is used as the methodology of the study. Results show that the author, publisher, translator and pro-translator scholars enacted disgraceful situations which can be attributed to subjective desirability.
\end{abstract}

Keywords: Domestication, foreignization, ideology, over- domestication, (un) faithful translation.

Cites as: Alwafai, S. (2019). Domestication Versus Foreignization: The case of translating AlSanea's Girls of Riyadh into English. Arab World English Journal for Translation \& Literary Studies, 3 (2). 139-151. DOI: http://dx.doi.org/10.24093/awejtls/vol3no2.12 


\section{1-Introduction}

Al-Sanea's Girls of Riyadh (2005) represents a literary revolt against the mainstream norms in Saudi Arabia at both content and form, since it addresses one of the major taboos, represented in laying bare the secret affairs of Saudi girls through narrating their stories and their different aspects of socialization in the Saudi Community. Al-Sanea was daring enough to discuss publicly in her novel highly controversial issues in Saudi Arabia, such as patriarchal society, gender relations, female vocational aspirations, political clout hierarchy. The novel is not written in Modern Standard Arabic; it is, however, written in vernacular speech, as informality and dialectal expressions and terms have dominated the scene in the novel to appeal to a broader readership in Saudi Arabia. The novel was forbidden in Saudi Arabia simply because it was accused of being an immoral work of art that helps spread vice and nudity and it was allowed to circulate in Saudi Arabia only after winning a court case (Sakr, 2008). Much as the original translator has ascertained the successful rendering of the polyphony of languages and dialects in the original text, the published version is devoid of such a stylometric signature. (Booth,2008).

A FrameNet (FN), a language resource pairing cognition with corpus linguistics, based on Fillmore's frame semantics (1976) is used to not only compute the resulting frames in the rendered version and but also to correlate such a cognitive realization in the source text. The vertical hierarchy of FN helps to attribute specific acts to their original conceptualization; therefore, linking the dots helps to understand the reported misconduct of the author, translator, publisher and other contributing scholars (Al-Ghadeer, 2006; Allen, 2015, Booth, 2008). The idea of the intervention of the author in the translation is critically examined in the light of Venuti's domestication versus foreignization, as it explains to what extent the interference of the author in the translated text could efface the translator's signature and manipulates and distorts the translated text. The remaining parts of the paper are made up of five parts. Part two buttresses the related works that tackle similar conflicting cases between the original author and the translator. Part three is meant to discuss the theoretical background that explains how translation theories are re-ushered towards studying the idea of effacing the translator's signature. Part 4 states the methodology of analyzing the (mis)conduct in the reported case study of translating Al-Sanea's "Girls of Riyadh" into English and the research questions of this study. Part 5 discusses the results. The last part draws the concluding remarks.

\section{2-Related works}

Al-Sanea's Girls of Riyadh has gained a wider popularity due to the hotness and daring nature of its themes, which represent a kind of resistance against the hegemonic long-life inherited tradition and deep-rooted cultural paradigms in Saudi Arabia. As such, several publishers were encouraged to translate this Chick-lit novel into several languages. The novel was translated by Penguin, a prestigious publishing house. The novel was translated by Marilyn Booth. The translated version was exposed to the intervention of the novelist, as she asked the translator for structural changes in the target text in order to adapt her novel culturally and ideologically to the norms and the values of the receiver. A negative result of such over-domestication is the distortion and misrepresentation of the original text that breaks with the idea of fidelity. However, the translator has refused to submit to her intervention in the translated work (Booth, 2008). In her 
published a review of Al-Sanea's Girls of Riyadh, Al-Ghadeer argues that Al-Sanea's novel is considered poor in terms of aesthetics, style, plot, and depth of characterization (2006, p.299).

The Arabic literature should not follow the cultural norms and ethical values of the Western literary works without changing the message of the original next nor does it distort its message or its structure (Booth, 2008). Booth tries to balance between domestication and foreignization, as he endeavors hard to present a conceptually comprehensible translation to the American reader without affecting the meaning of the original text. He refuses to change the dogma, the ideology and the values communicated through the original text. He colors his translation with the American mood to effectively communicate the meaning to the readership. However, the author attempts to make her novel more apt to the Western readership for commercial purposes. Therefore, she asks the translator to over-domesticate the translated text at the expense of the original text. Such intervention distorts and manipulates the original text and negatively affects the core message of the original novel. Resonating on their personal experience and ushering the author-translatorpublisher conflict to academia, Allen (2015), Hartman (2012) and Booth (2010) argued that the published version would have read better if Booth's foreignizing attitude was maintained. Stressing the sociological studies of translation, translation is not only regarded to be a representation of the contemporary socio-political realities but also an invisible medium that helps consolidate a prevailing attitude Asscher (2000). Translation is a rather complicated process which is a product of overlapped and intertwined factors such as author, publisher, translator's, audience and so on (Alvastad, 2014). These factors have an enigmatic force that make the translated text consistent with their nature.

The intervention of the author in the translation process may be classified under the rubric of self-translation. Popovič,(1976, p.19) defines self-translation as "the translation of an original work into another language by the author himself." In the same vein, Koller argues that a major problematic issue arising from self-translation is the idea of faithfulness, "as the author-translator will feel justified in introducing changes into the text where an "ordinary" translator might hesitate to do so" (1995, p.197). However, sometimes, self-translation is inevitable, when it is used as an inevitable tactic of resistance, by Afrikaans, against the ideology of apartheid (Kruger, 2012). Irrespective of reliability, Al-Sanea justified her interference with Booth's translation as an act of resistance against imposing the translator's ideology.

\section{3-Theoretical Framework}

Gutt (1996, p. 241) emphasizes that the ultimate goal of a translation is focused on translator's ability of rendering the implicit information in the original text and communicates it as clearly as possible in the target text, which demystifies the concept of the identical equivalence. Aside from the rarity of full-equivalent and the (un)intentionality of imposing the translator's voice, ideology or style, words live within a certain cultural system, either in verbal or in written discourses, which defy being typically transferred, across different languages and cultures, on the sameness scale (Boase-Beier, 2004).

Arab World English Journal for Translation \& Literary Studies 
Adamska-Sałaciak (2010, p.379) examines the available taxonomies of translation equivalence to present four major equivalence types: cognitive, explanatory, translational and functional.

(C) cognitive (semantic, systemic, prototypical, conceptual, decontextualised, notional);

(E) explanatory (descriptive);

(T) translational (insertable, textual, contextual);

(F) functional (situational, communicative, discourse, dynamic).

First, a cognitive equivalent is unconsciously recalled to the mind of a bilingual user regardless of the context, since it is "primarily concerned with the processes inside the minds of agents involved in communicative acts revolving around translated texts" (Sickinger, 2012, p.216).This equivalent type is related to the prototypical sense of a headword and is salient in back-translation. In this way, the cognitive equivalent seems to isolate the translated text from the contextual realities of the target text, and focuses on bringing the meaning into light in relation to the realities of the original text. In addition, it is suitable for conveying the overall meaning of the original text. The cognitive equivalent includes semantic equivalence, which "emphasizes the translation and the source text should achieve equivalent results in the expression" (Fu, 2017, p.165). It is a matter of convergence and symmetrical unity between the original lexical unit and the target one. However, such a cognitive equivalent is not applicable to the lexical units bearing cultural or religious implications, nor does it efficiently work with literary expressions and terms. It can be accurately used in the back translation. Second, explanatory equivalent is descriptive in nature and is almost used when the target language lacks a cognitive equivalent to the source language. In other words, the idea of the explanatory equivalent refers to paraphrasing or explaining a single lexical item through various words. When lexical units cannot be rendered through using the cognitive equivalent, the explanatory equivalent should be used as an alternative solution. Third, translational equivalence helps a translator considers the intertextual and contextual aspects of both source and target languages, including the linguistic aspects such as polysemous words, various language systems, collocational and idiomatic uses of a word, and other changeable factors. Therefore, translational equivalent provides a wide variety of equivalents for a headword. Finally, functional equivalence can be used to communicate the ST meaning without violating the TL rules. Producing a communicative translation, functional equivalents of the same word situationally change according to the translator, target reader and the mode (Adamska-Sałaciak, 2010).

Literary texts are difficult to render, and these texts are often described as untranslatable due to their syntactic ambiguity, lexical variety and density, accompanied by a totally distinct cultural, historical, esthetic and socio-political realities. The singular nature of literary texts often requires the intervention of the translator to adapt the source text both culturally and aesthetically to the norms and the standards of the target text. A literary text like a novel may include dialectal terms and expressions, which have no corresponding equivalence in the target culture. (BoaseBeier, 2004; House, 2014; Scott, 2017). One of the most applauded esthetic aspects is successfully rendering the register diversity especially in heteroglossic novels. Register is defined as "a semantic configuration that we associate with a particular situation type and characterized on the basis of three variables or components: field, tenor and mode" (Marco, 2000, p.3). Although the 
detailed implication of register analysis for literary translation can be manifold, only a few items are singled out for illustration: degree of technicality and marked field mixing with regard to the variable of field, terms of address, and modality with respect to tenor, and the interplay between grammatical complexity and lexical density as markers of oral and written language in the area of mode.

Regardless of the nuisance of providing equivalence at the lexical, sentential, pragmaticstylistic levels, the dichotomy of domestication and foreignization complicates the nonstandardized criteria of translation tactics. Venuti (1986) dichotomizes 'alienating/exotizing' and 'naturalizing' translation approaches as 'foreignization' and 'domestication' respectively. Foreignization, on the one hand, "entails choosing a foreign text and developing a translation method along lines which are excluded by dominant cultural values in the target language" (Venuti 1997, p. 242). Domestication, on the other hand, embraces 'an ethnocentric reduction of the foreign text to [Anglo-American] target-language cultural values' (Munday,2013, p.6). Domestication can be described as "indirect translation", "covert translation", "naturalization", "illusionism", "communicative translation", "instrumental translation" and "participative reception." Domestication is more convenient for translating a literary text since it naturalizes the translated text and turns it more comprehensible to the receiver, as the text is oriented toward the norms and the cultural values and ideology of the targeted text (Ožbot, 2016).

In a trial to reduce the noise in such a complex multi-dimensional crisis, natural language processing (NLP) tools and cognitive theories have presented practical instruments and linguistic resources which can achieve similar effective conceptualization and psycholinguistic impact of the rendered text. Such interoperability has also made an inter-language to which all languages can be paired. Thus, the problem of equivalence has been dashed and replaced by "semantic similarity". This success is attributed mainly to WordNet (Fellbaum, 1998) and FrameNet (Ruppenhofer et al., 2006) and to other similar NLP-based language resources. Princeton WordNet (WN), built after the evidenced structure of the "mental lexicon" in a trial to understand human semantic memory, provided a fine-grained division of meaning sorted in a hierarchical hypernym/hyponym structure that is exported from an ontological processing.

Replacing the alphabetic sorting (orthography) by the thematic and the morphological perspective, save for inflectional morphology in WN's interface, by the relational semantic link, is enabled to connect WN's lexical entities into a large network of linguistically labeled nodes. Of these relations, WN is mainly concerned with lexical inheritance system; giving a brief definition (gloss) for every sense; enumerating 'coordinate terms' to cluster hyponyms, which share the same hypernym and lies at parallel distance of semantic relatedness. Synonymous words, or synsets, are linked via an "equivalence relation", to an interlingual index, for rendering a multilingual expansion and for comparing coverage, relations, and overall lexicalization patterns across the covered languages (Fellbaum 2014; Miller, and Fellbaum 2007). The paradigmatic relations assigned in WN, which denote links and semantic relations between lexical units within a language system, include hypernymy, hyponymy, troponymy, meronymy, antonymy, synonymy, and entailment (among verbs). The main semantic relation among words is synonymy, as between the

Arab World English Journal for Translation \& Literary Studies 
words assume and suppose and between shame and disgrace, which are grouped into unordered sets (synsets).

The criterion for joint synset membership is merely that the words denote the same concept. Each of WordNet's synsets is linked in turn to other synsets by means of a small number of "conceptual relations." Also, one-to-many mappings of word forms and word meanings govern polysemy and synonymy. A single word form expressing several meanings is a case of polysemy. Highly polysemous words in English are check, case, and line. Polysemy requires the reader or listener to identify the context-appropriate, intended sense of the word form. Hyponymy is a semantic relation between word meanings: e.g., tree is a hyponym of plant while obloquy and odium are hyponyms of shame. Hyponymy is, therefore, a relationship found in many nouns, in quite a number of verbs, and in some adjectives. Its major significance for lexicographers is that the 'genus expression' in a definition should be the hypernym of the headword. Hyponymy holds more often between nouns while antonymy 'belongs' more to adjectives. Meronymys reflect the relationship of part to whole and vice versa (Fellbaum 2014; Miller \& Fellbaum 2007). Studying all these relations among senses has expanded and enriched the scope of translation theories about "translation equivalence".

The linguistic unit employed by a user is the figure, while the human experience behind it is the ground (Fillmore,1976). The semantic frames theory is deeply rooted in cognitive psychology. It is based on the figure-ground gestalt trend. Any experience in the physical world can be segmented in terms of figure and ground. Figure is the predominant constituent in the figure-ground system; it is placed within certain surroundings; ground. Human experience here refers to the encyclopedic knowledge associated with this linguistic unit, 'frame'. Fillmore (1976) the founder of frame semantics theory, describes a frame as:

any system of concepts related in such a way that to understand any one of them you have to understand the whole structure in which it fits; when one of the things in such a structure is introduced into a text, or into a conversation, all of the others are automatically made available. (p.373)

FrameNet $(\mathrm{FN})$, a language resource pairing cognition with corpus linguistics, which is based on Fillmore's frame semantics, enrolls more than 13,000 lexical entities, which are designated 'lexical units' on being assigned to a specific frame. The basic constituents of FN are lexical units and frame elements (FEs). Between different frames, FEs liaise to each other and create interconnectedness between pertinent frames. Both LUs and FEs are annotated and featured, using large-scale American and British corpora, to specify dynamic uses and lexical valence. Connecting frames, which share broad and complex cognitive parameters, cognitive matrices develop. These are inheritance, perspective on, uses, subframe of, see also, causes and inchoative of. FN specifies a great deal of structural information both within and among frames. For frame identification we make use of frame-evoking lexical units, the (lemmatized and POS-tagged) words and phrases listed in the lexicon as referring to specific frames. For example, listed within the Desiring frame are 54 lexical units.

Arab World English Journal for Translation \& Literary Studies 
They include 12 adjectives (covetous, desired, desirous, dying, eager, hungry, interested, loath, raring, reluctant, spoiling and thirsty); 17 nouns (ambition, aspiration, craving, desire, hankering, hope, hunger, impulse, longing, lust, thirst, urge, wants, will, wish, yearning and yen); 2 prepositions (in hopes of and in the hope of) and 23 verbs (ache, aspire, care, covet, crave, desire, fancy, feel like, hanker, hope, hunger, itch, long, lust, pine, thirst, want, will, wish(that), wish, yearn and yen). Of these lexical units, verbs are the most powerful in evoking frames. Thus, in computational tasks, identifying the predicate and its dependent arguments in the sentence is dependent on the main verbs and the syntactic realization captured from the surrounding context.

Given that FN reports a general frame for 'disgraceful situations', this paper the lexical units of this frame as well as the lexical units of the pertinent ones (figure 1) to be measured, and their translations, in the published translation of the novel as well as in the published articles about the scandalous act of the interfering author and publisher.

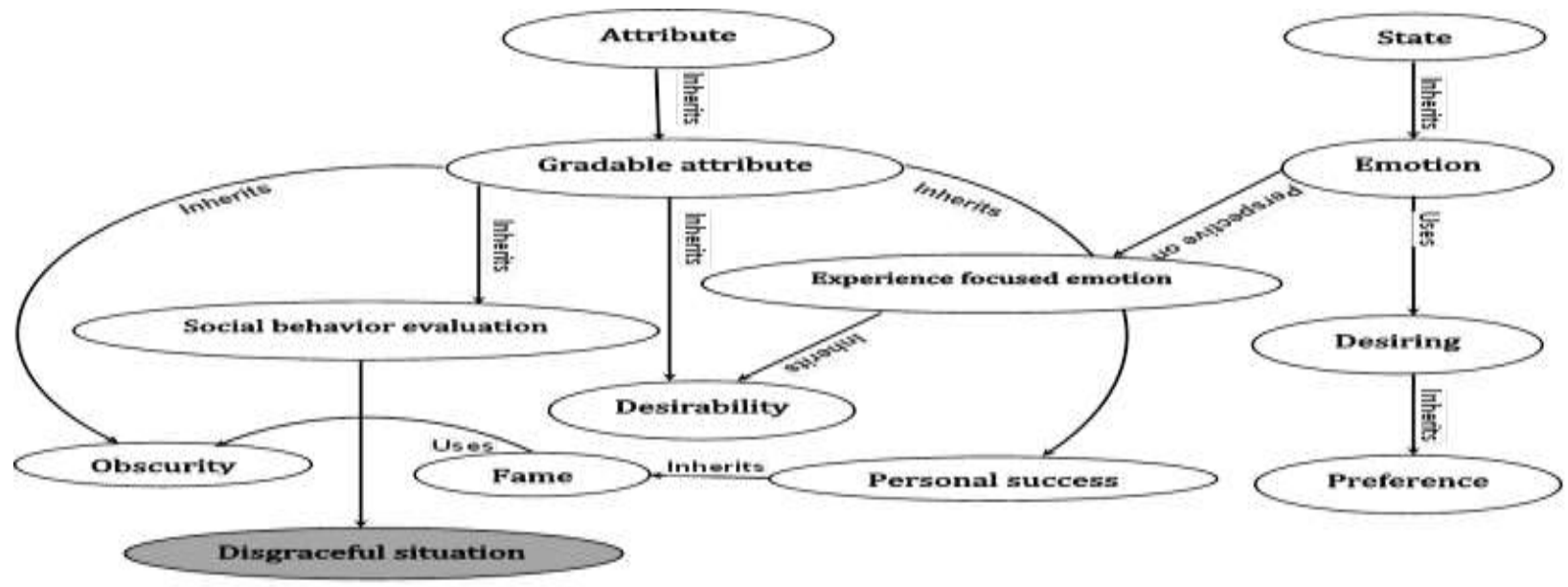

Figure 1. Frame-to-Frame relations of 'Disgraceful situation' in FN

\section{4-Methodology}

This study attempts to answer three main questions. First, how (un)faithful is the published English translation of Al-Sanea's Girls of Riyadh to the original Arabic text in terms of evoking the same conceptual frames and maintaining the same lexico-grammatical relations?

Second, how objective are the criteria of evaluating Al-Sanea's interference with Booth's translation in the relevant academic articles?

Third, what implications can be concluded from this case study as well as from similar cases in the translation literature?

\section{Experiment 1}

To answer the first question, I measured computationally the number of the evoked frames and the frequency of evoking them in source and target texts. I also compiled a parallel corpus of both 
source and target texts to study the lexicogramatical relations, retrieve the keywords and clusters and visualize the distributional semantic relations of selective keywords. For creating a parallel corpus, I preprocessed the data by removing punctuation marks, non-words, redundant character, repetitions and symbols. The source and target texts were aligned at the sentence level. Then, the parallel corpus was uploaded on Sketch Engine to be analyzed.

Lexical units expressing desiring and desirability were measured and so were the lexical units of the relating frames (Group 1). Other corpora, representing the scholarly articles which addressed the publisher's and the author's unethical conduct, were similarly processed. Penguin owns the translation and I am not at liberty to supply it.

\section{Experiment 2}

To answer the second questions, all articles about translating Al-Sanea's Girls of Riyadh were collected. The exemplified mistranslations were annotated. The criteria of translation Al-Sanea's discarded were also classified. The classified errors were generally measured in the published version of the English translation to quantitatively evaluate such an accusation.

\section{Experiment 3}

Rejuvenating Scheherazade, the anecdotal Arabic female narrator, Al-Sanea's "Girls of Riyadh" was translated into approximately 18 languages from 2007 to 2015. The English, French, German, Croatian, Danish, Greek, Italian, Portuguese and Romanian translations are available on Amazon. We back translated the French, German and Croatian translations to English and Arabic for matching their similarity to the primary version (original) and to the second primary (selftranslation) one. Multlingual WN was used to measure the lexical coverage, richness and familiarity of each version.

\section{5-Results and Discussion}

The published English translation of Al-Sanea's Girls of Riyadh evoked the same frames the original Arabic text triggered. However, the difference in the incidence of evoking some conceptual frames was statistically significant. These frames included 'Attempt_suasion', 'Cause_emotion', 'Desiring', 'Disgraceful_situations', 'Experience_focused_emotion', 'Fame', 'Gradable_attribute' and 'sensation'. On the one hand, the retrieved Arabic keywords included negation particles, characters names, spatial references and narration verbs (Group 2).

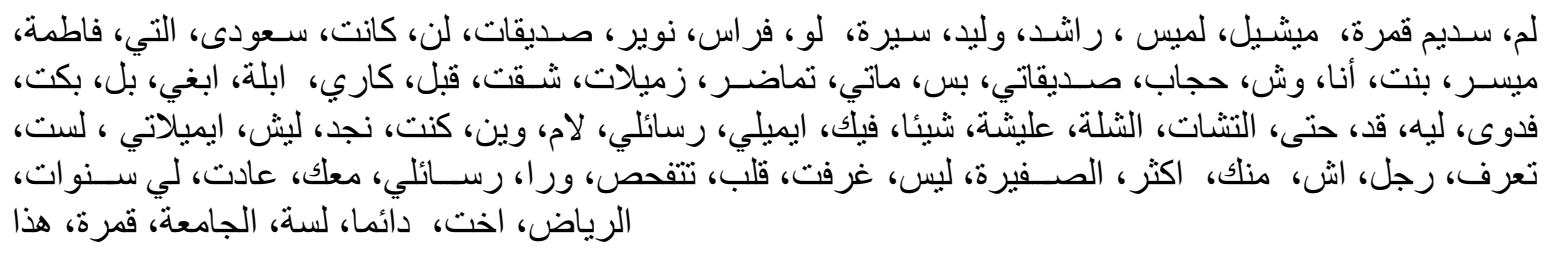

Group 2. Keywords retrieved from the Arabic corpus

On the other hand, keywords retrieved from the English corpus included more name entities, social roles and semantic agents with no reference to the narration verbs and negation particles (Group 
3). Taken together, this suggests that the narration style has been modified in the published English translation.

Sadeem, Gamrah, Lamees, Michelle, Riyadh, Firas, Saudi, Rashid, Faisal, Um, Waleed, Nuwayyir, seerehwenfadha7et, Subject, Nizar, Tariq, Fatimah, Arabia, Matti, Tamadur, Tahir, Khobar, Hessah, Nuri, Jeddah, Musa, Kari, Ramadan, Shiite, Badriyyah, Sultan, thobe, Hamdan, Saleh, Aquarius, Meshaal, Hijab, Scrapbook, Shimagh, Fadwa, Arwa, Auntie, Bedouin, Khalid, Naflah, Jumana, Najd, Shillah, Saddoomah, Olaisha, Najdi, Chelle, Shahla, Wallah, Shari, Sadeem, Horaimli, Mashael, Qabbani, Sheikh, Kuwaiti, Gamrah, Ghadah, Malaz, Hijazi, Abdulrahman, Shisha, Fiancée, Milkah, Gammoorah, Sattam, Mudi, Gradu, Qusmanji, Lamees, Shaikhah, Jeddawi, Tanbal, Eqal, Alhamdu, Lillah, Fatin, Qatif, Divorcée, Riyal,

Group 3. Keywords retrieved from the English corpus

Because processing English corpora is more productive than processing Arabic ones, the retrieved clusters in the English translation (Group 4) were manually traced back to the original text. All clusters were detected in both source and target texts.

Blue scrapbook, Marriage contract, Saudi society, Eastern province, Dance floor, Real name, Whole time, Eastern region, Medical student, First love, Milkah period, Engagement period, Wedding night, Other girl, Wedding party, Bad luck, Dawn call, Saudi guy, Capricorn man, Young Saudi man, Famous Saudi singer, Saudi singer, Gemini woman, Hadith collection, Saudi man, Reception room, Only love, Wedding celebration, First girl, Marriage proposal, Twin sister, First marriage, TV program, U r, Real man, Old home, Good girl, Islamic law, Summer break, Other man, Paper bag, Chat room, Perfect American accent, Eldest aunt, Enormous bag, Poor bride, Ethiopian driver, Skyblue scrapbook, Little Shillah, Female medical student, White thobe, Egyptian actor, Hair cover, Blank message, Religious type, Natural distribution, Few min, Enormous hall, Friend Michelle, Nearby mosque, Rubber ducky, Legal husband, Strange guy, Dental student, Innocent face, Confident smile, Quick mind, Conservative society, Same sky, Bouquet toss, Invitation card, Bright red lipstick, Single evening, Big nose, Ordinary woman, Islamic country, Heavy makeup, Beautiful love, Native city, Ultimate destiny, Holy month, Worldly life, Successful marriage, Closet door, American accent, Signing ceremony, True reason, Prayer service, Bad girl, First wedding, Prayer time, Grocery shop, Black bear, New husband, Red lipstick, Cell phone number, First son, Daily schedule.

\section{Group 4. Clusters retrieved from the English corpus}

The heteroglossic effect of the Arabic novel has been totally effaced in the English translation despite its value for sociolinguistic studies. The register was not successfully rendered. The distributional semantics of the word friend(s) in Arabic (Figure 2) and English (Figure 3) were totally different. This heightens the impression that Al-Sanea modified the narration in the English version. 


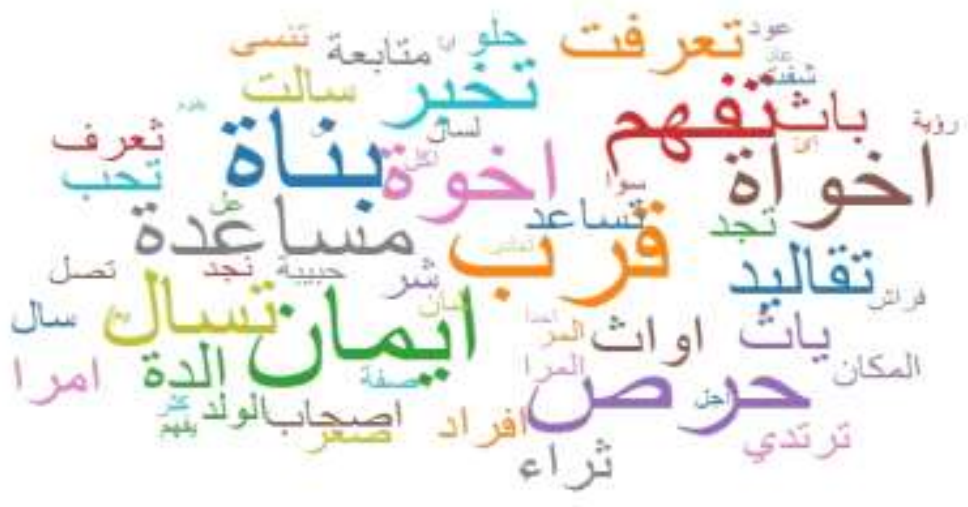

Figure 2. Distributional semantics of the word friend in the English translation

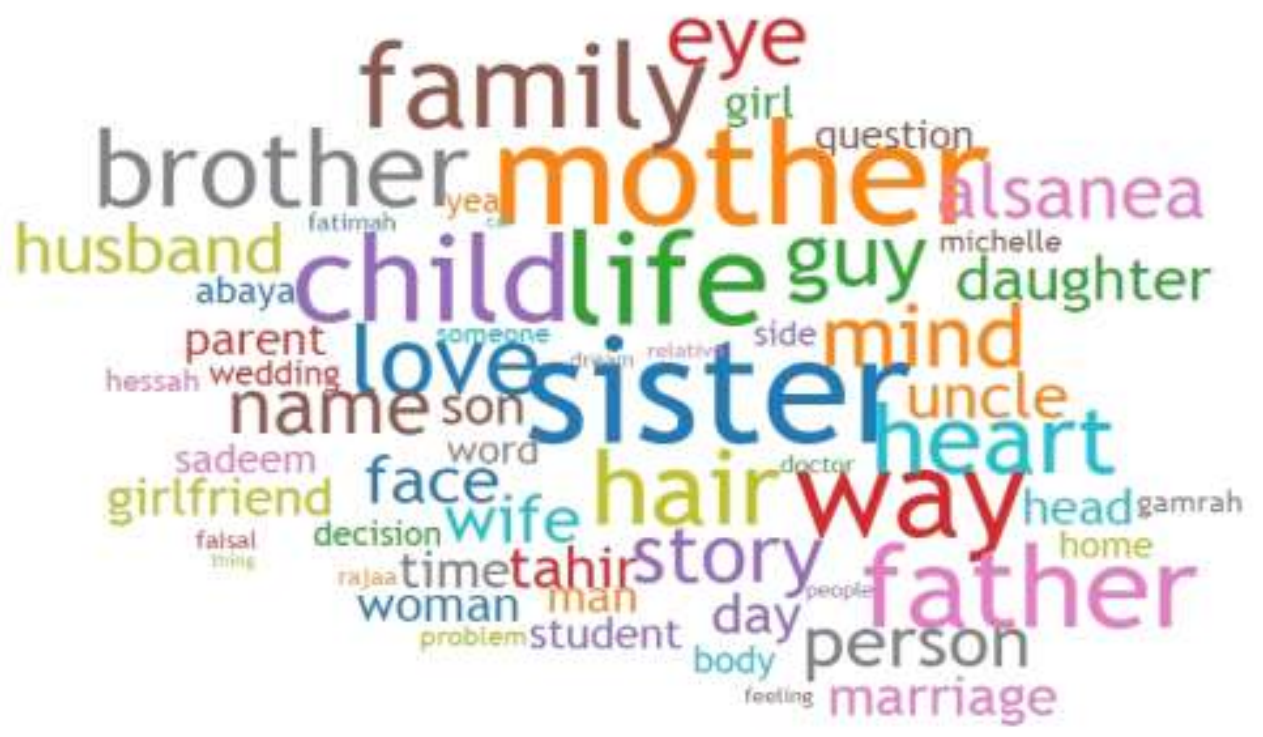

Figure 3. Distributional semantics of the word friend in the English translation

To enumerate the criteria of evaluating Al-Sanea's interference with Booth's translation in the published academic articles, all articles about translating Al-Sanea's "Girls of Riyadh" were collected.

The main accusation leveled at the published translation is over-domestication. However, Al-Sanea retained several relexified words to maintain the foreignizing effect. Examples include Allah, Masha'lla , Eqal and thobe among others. Booth (2008) emphasized that she wished to replace 'Allah' by 'Lord' as is consistent with Christianity. Booth (2008) did draw on Venuti's

Arab World English Journal for Translation \& Literary Studies 
invisibility and Baker's re-narration. Although the two theoretical perspectives are incongruent, objective evaluation of the translator's voice cannot be assessed because Peguin retains Booth's translation.

More important, academic implications can be concluded from this case study as well as from similar cases in the translation literature. However, the case of self-translation, in which the writer enjoys an authority and a liberty that other translators usually lack, can prove effective in resisting imposed ideologies. This goes hand in hand with Afrikaans' tactics for resisting the ideology of apartheid (Kruger, 2012).

On comparing the three non-English studied translations to the published one, the back translation was more similar to the published version than to the original Arabic text. This suggests that either Al-Sanea has stipulated that the translation must use the second primary version (selftranslation) or the translators used the published English novel "Girls of Riyadh" as a pivot text. Interestingly, the Croatian and French translations have domesticated the name entities especially the names of the major characters. This was not heralded as a breach to Venuti's invisibility.

\section{6-Conclusion}

Controversial as Al-Sanea's Girls of Riyadh seems to be, lessons can be learnt from the publisher's, translator's and author's attitude towards stylometric authority of source and target texts. This study suggests that Al-Sanea has structurally changed the narration style in her selftranslated version. However, the conceptualization of central themes remains similar. This might explain why newer translations are given to date. It is also suggested that professional translators customize their discussion of the proposed translation theories in the most convenient way that serves their agenda. Therefore, using NLP and cognitive tools may be recommended to avoid, as much as possible, subjective evaluations.

More important, cases of self-translation should be studied adequately with reference to the stylometric signature and matriculation of practical translation. Corpus tools can provide empirical evidence in descriptive literary studies. In this case, Booth's translation, if available, would add much to exploring any plagiarized style and to fathoming the mental spaces of the translator. Lexical richness and diversity, translator's signature and voice as well as authorial extended liberty should be assessed on reporting similar cases.

\section{About the author:}

Salwa Alwafai, Ph.D. in Linguistics and Translation (Delhi University), A faculty member at Al-Baath University (previously), Assistant Prof. of Linguistics \& Translation, Department of English Language, College of Arts, Imam Abdulrahman Bin Faisal University ( IAU), Dammam, KSA, (currently). ORCID: https://orcid.org/0000-0002-1424-8897 


\section{References}

Adamska-Sałaciak, A. (2010). Examining equivalence. International Journal of Lexicography, 23(4), 387-409.

Al-Ghadeer, M. (2006). Girls of Riyadh: A new technology writing or chick lit defiance'Banat AlRiyad'['Girls of Riyadh']. Journal of Arabic Literature, 37(2), 296-302

Allen, R. (2014). Criteria for Translation: the Case of the Arabic Best-Seller Revisited. Rivista degli studi orientali, 87(1/4/1), 103-114.

Allen, R. (2015). Translating Arabic Fiction. Journal of Arabic Literature, 46(2-3), 157-167.

Alsanea, R. (2005). Girls of Riyadh. Dar Alsaqi. Lebanon.

Alsanea, R. (2007). Girls of Riyadh. Penguin UK.

Alsanea, R. (2008). Girls of Riyadh [Devojke iz Riyada]. Naklada Ljevak. Croatia.

Alsanea, R. (2008). Girls of Riyadh: A novel [Die Girls von Riad: Roman]. Pendo. Germany.

Alsanea, R. (2012). Girls of Riyadh [Les filles de Riyad]. Pocket. France.

Alvstad, C. (2014). The translation pact. Language and Literature, 23(3), 270-284.

Atkins, B. S., \& Rundell, M. (2008). The Oxford guide to practical lexicography. Oxford University Press

Bassnett, S., \& Trivedi, H. (2012). Postcolonial translation: Theory and practice. Routledge

Boase-Beier, J. (2004). Translation and style: A brief introduction. Language and Literature, 13(1), 9-11.

Booth, M. (2008). Translator v. author (2007) Girls of Riyadh go to New York. Translation Studies, 1(2), 197-211

Booth, M. (2010). "The Muslim Woman" as Celebrity Author and the Politics of Translating Arabic: Girls of Riyadh Go on the Road. Journal of Middle East Women's Studies, 6 (3), 149182.

Cid Abasolo, K. (2015) Literary self-translation from basque. Revista de Filologia Romanica 2015(ANEJO IX), 177-192

Cruse, D. A. (1986). Lexical semantics. Cambridge University Press.

Cruse, D. A. (2017). The lexicon. The handbook of linguistics, 235-254

El-Ariss, T. (2012). Fiction of Scandal. Journal of Arabic Literature, 43(2-3), 510-531.

Fellbaum, C. (2014). Large-Scale Lexicography in the Digital Age. International Journal of Lexicography, ecu018.

Fellbaum, C. ed. (1998). WordNet: An electronic lexical database. Cambridge, MA: MIT Press.

Fillmore, C. J. (1976). Frame semantics and the nature of language. Annals of the New York Academy of Sciences, 280(1), 20-32.

$\mathrm{Fu}$, L. (2017) On Semantic Equivalence in English-Chinese Translation. Advances in Social Science, Education and Humanities Research,117,164-167.

Gutt, E. A. (1996). Implicit information in literary translation: A relevance-theoretic perspective. Target. International Journal of Translation Studies, 8(2), 239-256.

Hartman, M. (2012). Gender, genre, and the (missing) gazelle: Arab women writers and the politics of translation. Feminist Studies, 38(1), 17-49.

Hetényi, Z. (2018). Translating self-translation and the units of the translation: the case of Nabokov. Studia Slavica Academiae Scientiarum Hungaricae, 63(1), 49-55.

Arab World English Journal for Translation \& Literary Studies 
House, J. (2014). Translation quality assessment: Past and present. In Translation: A multidisciplinary approach (pp. 241-264). Palgrave Macmillan, London.

Koller, W.(1995). The Concept of Equivalence and the Object of Translation Studies. Target. International Journal of Translation Studies.7(2),191-222.

Kruger, A. (2012). Translation, self-translation and apartheid-imposed conflict. Journal of Language and Politics, 11(2), 273-292

Marco, J. (2000). Register Analysis in Literary Translation: A Functional Approach. Fédération International des Traucteurs (FIT) Revue Babel, 46(1): 1-19.

Miller, G. A., \& Fellbaum, C. (2007). WordNet then and now. Language Resources and Evaluation, 41(2), 209-214.

Munday, J. (2013). Introducing translation studies: Theories and applications. Routledge

Murphy, M. L. (2003). Semantic relations and the lexicon: Antonymy, synonymy and other paradigms. Cambridge University Press.

Popovič, A. (1976). A Dictionary for the Analysis of Literary Translation. University of Alberta: Edmonton

Ožbot, M. (2016). Foreignization and Domestication: A View from the Periphery. In Rereading Schleiermacher: Translation, Cognition and Culture (pp. 277-289). Springer, Berlin, Heidelberg.

Ruppenhofer, M. Ellsworth, M. Schwarzer-Petruck, C. R. Johnson \& J. Scheffczyk (2006). FrameNet II: Extended theory and practice

Sakr, N. (2008). Women and media in Saudi Arabia: Rhetoric, reductionism and realities.British Journal of Middle Eastern Studies. 35 (3), 385-404 . doi:10.1080/13530190802525197

Sickinger, P. (2012). Mental Models and Linguistic Cues: Investigating the Interface Between Language and Mental Representation Across Cultures. 35th International LAUD Symposium: Cognitive psycholinguistics: Bilingualism, cognition and communication, 125-146. Essen: LAUD.

Scott, C. (2017). Translating the perception of text: Literary translation and phenomenology. Routledge

Venuti, L. (1986). The translator's invisibility. Criticism, 28(2), 179-212 Venuti, L (1997). The translation studies reader. New York: Routledge 